\title{
Identifikasi Logam pada Endapan Lindi Hitam Hasil Samping Proses Bioetanol sebagai Salah Satu Konsep dalam Pemurnian Lignin
}

\section{Identification of Metal Content in the Precipitation Recovered from By Product of Bioethanol Process as a Concept of Lignin Purification}

\author{
Achmad Hanafi Setiawan ${ }^{1}$ \\ ${ }^{1}$ Pusat Penelitian Kimia LIPI \\ Kawasan PUSPIPTEK Serpong, Tangerang Selatan 15314 \\ Corresponding author: achmad.hanafi@gmail.com
}

\section{AR TICLE INFO \\ Article history \\ Received date : 8 March 2016 \\ Revised date : 9 June 2016 \\ Accepted date :10 June 2016 \\ Available online at: \\ http://kimia.lipi.go.id/inajac/index.php}

\author{
Kata kunci: \\ lignin, lindi hitam, karakterisasi, \\ TG/DTA, TPC, EDS, PSA
}

Keywords:

lignin, impurities, bioethanol,

TG/DTA, TPC, EDS, PSA

\begin{abstract}
Abstrak
Lignin merupakan polimer alam yang bersifat amorf, tidak beracun dan merupakan hasil samping dari proses delignifikasi pada proses bioetanol generasi kedua. Produk lignin dari proses ini biasanya masih mengandung selulosa, hemiselulosa, dan senyawaan anorganik, sehingga kontaminan tersebut harus dihilangkan pada proses pemurnian. Penelitian ini difokuskan hanya pada penghilangan kotoran anorganik kecuali silika. Lindi hitam diperoleh dari proses delignifikasi tandan kosong kelapa sawit yang dilakukan dengan menggunakan $5 \%(\mathrm{~b} / \mathrm{b})$ larutan $\mathrm{NaOH}$ dengan rasio padatan dan larutan 1: 5, pada kondisi proses $150^{\circ} \mathrm{C}, 5$ bar selama 30 menit. Endapan lignin diperoleh dengan menambahkan 50\% (v/v) asam sulfat ke dalam dua larutan lindi hitam sedemikian hingga larutan mencapai harga $\mathrm{pH}=12$ dan $\mathrm{pH}=1$. Kemudian masing-masing larutan disentrifus pada putaran $4000 \mathrm{rpm}$ selama 15 menit. Setelah disaring dan dikeringkan pada suhu $50^{\circ} \mathrm{C}$ selama 16 jam, sampel kemudian dikarakterisasi dengan TG/DTA dan hasilnya dikonfirmasi dengan uji TPC, sedangkan komposisi unsur-unsur anorganik yang terkandung dalam abu dianalisis dengan EDS, dan distribusi partikelnya diukur dengan PSA. Hasil penelitian menunjukkan bahwa sampel yang berasal dari larutan dengan $\mathrm{pH}=12$ menghasilkan $28 \%$ kadar abu dan mengandung sembilan elemen yang jumlahnya berkisar antara 1,3-18,0\%, sedangkan sampel yang berasal dari larutan dengan $\mathrm{pH}=1$ hanya mengandung $0,9 \%$ kadar abu dan mengandung empat unsur anorganik yang jumlahnya berkisar antara $0,2-1,8 \%$. Terjadi penurunan rata-rata ukuran partikel sampel dari $262 \mu \mathrm{m}$ sampai $59 \mu \mathrm{m}$ dengan perubahan kondisi larutan dari $\mathrm{pH}=12 \mathrm{ke} \mathrm{pH}=1$.
\end{abstract}

\section{Abstract}

All living plants have lignin, second most ubiquitous natural polymer behind cellulose. Lignin is an abundant non-toxic amorphous natural polymer and inexpensive by product of paper industry. Nowadays, lignin is gaining importance as a potential source for fine chemicals, however they need to be relatively pure with low ash. Since the lignin products are usually contaminated with cellulose, hemicelluloses and other inorganic impurities, their purification is needed for further enzymatic or chemical processing into target products. In this work, black liquor was obtained from the pretreatment process of biomass which was carried out using a 5\% (w/w) $\mathrm{NaOH}$ solution with a solid to liquid ratio of $1: 5$, at $150^{\circ} \mathrm{C}, 5$ bars for 30 min. Lignin was recovered from the liquor by adding $50 \%(\mathrm{v} / \mathrm{v})$ sulphuric acid until the black liquor reached $\mathrm{pH}=12$ to $\mathrm{pH}=1$. The liquor was centrifuged at $4000 \mathrm{rpm}$ for $15 \mathrm{~min}$ and the residue contain lignin was separated and dried at $50^{\circ} \mathrm{C}$ overnight. The dried samples then were characterized by means of thermal analysis. Temperature ranges for obtaining of ash were identified by TG/DTA, then was confirmed by the test of TPC, while element which implied in the ash analyzed with SEM/EDS. In

“Identifikasi Logam pada Endapan Lindi ...": A. H. Setiawan | 73 
addition, the distribution of particles was analyzed by PSA. The TPC and $E D S$ results show that the sample prepared at the $p H=12$ has $28.9 \%$ ash containing nine elements range from 1.3-18.0\%, whereas it is at the $\mathrm{pH}=1$ has $0.9 \%$ ash containing four inorganic elements only ranges from 0.2-1.8 $\%$. The average of particle size of sample is decreasing from $262 \mu \mathrm{m}$ to 59 $\mu \mathrm{m}$ with the increasing of the precipitation from $\mathrm{pH}=1$ to $\mathrm{pH}=12$.

(C) 2016 Indonesian Journal of Applied Chemistry. This is an open access article under the CC BY-NC-SA license.

\section{PENDAHULUAN}

Telah terdokumentasi dalam pustaka bahwa strategi pemurnian polimer alam seperti halnya lignin akan tergantung kepada tingkat keberadaan pengotornya. Bentuk pengotor dapat berupa senyawaan yang bersifat kimia organik maupun anorganik yang jumlahnya tergantung pada proses awal yang digunakan. ${ }^{[1]}$

Unsur utama pada biomassa jenis lignoselulosa adalah lignin, selulosa dan hemiselulosa. Lignin adalah biomaterial terbarukan yang terbesar kedua setelah selulosa yang sudah dimanfaatkan sebagai material pelapis adhesive, binder, composite dispersant dan bahan kimia aromatik dan emulsifier. ${ }^{[2,3]}$ Lignin merupakan polimer polifenol amorf yang utamanya terdiri dari guaiacylpropane, syringylpropane dan hydroxyphenylpropane. ${ }^{[4]}$

Senyawaan lignin dapat dihasilkan dengan beberapa metode seperti proses Kraft, proses alkali, steam explosion dan proses dengan organosolv. Pada proses produksi bioetanol dengan bahan baku biomassa lignoselulosa, lindi hitam adalah produk samping dari proses delignifikasi. ${ }^{[5,6]}$ Karena lindi hitam ini biasanya masih mengandung selulosa, hemiselulosa dan kotoran kimia anorganik, maka pemurnian diperlukan untuk menghilangkan pengotor lignin tersebut. ${ }^{[1]}$ Jumlah pengotor anorganik umumnya dapat ditunjukkan dengan kandungan abu.

Salah satu strategi pemurnian dari lignin adalah mempelajari properti dari pembentukan abu tersebut, seperti $\mathrm{pH}$ optimum dan suhu kalsinasi, kadar abu dan elemen yang terkandung dalam residu yang dihasilkan dengan kondisi preparasi yang berbeda dan elemen yang terkandung dalam abu yang dihasilkan. ${ }^{[7,8]}$

Pada penelitian sebelumnya, karakterisasi padatan yang dihasilkan tanpa melalui proses penyaringan pada $\mathrm{pH}=1$ sampai $\mathrm{pH}=12$ dengan metode gravimetri, ${ }^{[5,9]}$ ditemukan bahwa yield dari padatan dengan kondisi larutan asal pH tinggi lebih kecil dari padatan yang dihasilkan pada kondisi larutan asal dengan $\mathrm{pH}$ rendah. Sehingga dalam penelitian ini hanya akan dilihat keberadaan pengotor pada kondisi $\mathrm{pH}=1$ dan $\mathrm{pH}=12$ sebagai batas kondisi ekstrim $\mathrm{pH}$ yang sudah dilakukan.

Dalam industri kebutuhan level kemurnian bervariasi tergantung pada fungsi lignin yang dituju, antara lain sebagai perekat, ${ }^{[10]}$ sebagai bahan kosmetik. ${ }^{[11]}$ Ini ada hubungannya dengan kandungan selain lignin dalam lindi hitam dapat berupa senyawaan organik (seperti: selulosa dan hemiselulosa selulosa) atau bahan anorganik (logam dan silika), namun dalam penelitian ini karakterisasi difokuskan untuk melihat kemurnian padatan lignin ditinjau dari jumlah pengotor anorganik terutama logam berbahaya.

\section{METODE}

\subsection{Bahan Kimia dan Contoh Lindi Hitam}

Natrium hidroksida $(\mathrm{NaOH})$, p.a. dan asam sulfat $\left(\mathrm{H}_{2} \mathrm{SO}_{4}\right)$, p.a. dari Merck; sampel lindi hitam diperoleh sebagai produk proses delignifikasi tandan kosong kelapa sawit sebagai bagian dari proses produksi bioetanol di Pusat Penelitian Kimia-LIPI. Spesifikasi dari lindi hitam ini adalah $\mathrm{pH}$ 14, desitas $1,03 \mathrm{~g} / \mathrm{ml}$, dan kadar padatan kering total $66,9 \mathrm{~g} / \mathrm{L}$. 


\subsection{Penyiapan sampel padat}

Lindi hitam diperoleh dari proses delignifikasi tandan kosong kelapa sawit dengan menggunakan 5\% (b/b) larutan $\mathrm{NaOH}$ dengan rasio solid to liquid $1: 5$, pada temperatur $150^{\circ} \mathrm{C}$ dan tekanan 5 bar selama 30 menit. Lignin dalam lindi hitam diendapkan kembali dengan menambahkan 50\% (v / v) asam sulfat sampai cairan hitam mencapai $\mathrm{pH}=$ 12 dan $\mathrm{pH}=1$. Larutan yang dihasilkan masing-masing disentrifuse pada $4000 \mathrm{rpm}$ selama 15 menit dan residu yang mengandung lignin disaring dan kemudian dikeringkan pada $50^{\circ} \mathrm{C}$ selama 16 jam.

Sampel padatan kering dikarakterisasi dengan TG/DTA dan TPC. Sisa contoh dari percobaan TPC kemudian dianalisis dengan EDS. Analisa termogravimetri dari sampel dilakukan dengan aliran udara ruang menggunakan TGA Q50 pada rentang temperatur 25 sampai $600^{\circ} \mathrm{C}$, dengan kecepatan aliran udara $\quad 5^{\circ} \mathrm{C} /$ menit. Temperature Programmed Calcinations (TPC) dilakukan menggunakan Thermolyne Programmable Furnace dengan aliran udara luar untuk mendapatkan $\%$ abu dalam jumlah banyak.

Sebelum dikalsinasi pada $575^{\circ} \mathrm{C}$ selama tiga jam, sampel dipanaskan dari $25^{\circ} \mathrm{C}$ ke $575^{\circ} \mathrm{C}$ dengan kecepatan $5^{\circ} \mathrm{C} /$ menit. Kadar abu dihitung dari berat residu hasil kalsinasi dibagi dengan berat sampel awal dan mengalikan dengan $100 \%$. Analisa elemen dilakukan dengan menggunakan SEM-EDS, JEOL, 6510 (LA), sedangkan distribusi ukuran partikel dianalisis dengan Beckman Coulter LS Particle Analyzer. Sampel diencerkan dengan aquades. Setelah itu diobservasi difraksinya dengan pengukuran pada kisaran $0,4 \mu \mathrm{m}$ sampai 950 $\mu \mathrm{m}$.

\section{HASIL DAN PEMBAHASAN}

\subsection{Analisis Termografimetri}

Termogram TGA/DTA dari senyawaan lignin yang diendapkan dengan kondisi $\mathrm{pH}$ yang berbeda dapat dilihat pada Gambar 1 dan Gambar 2.

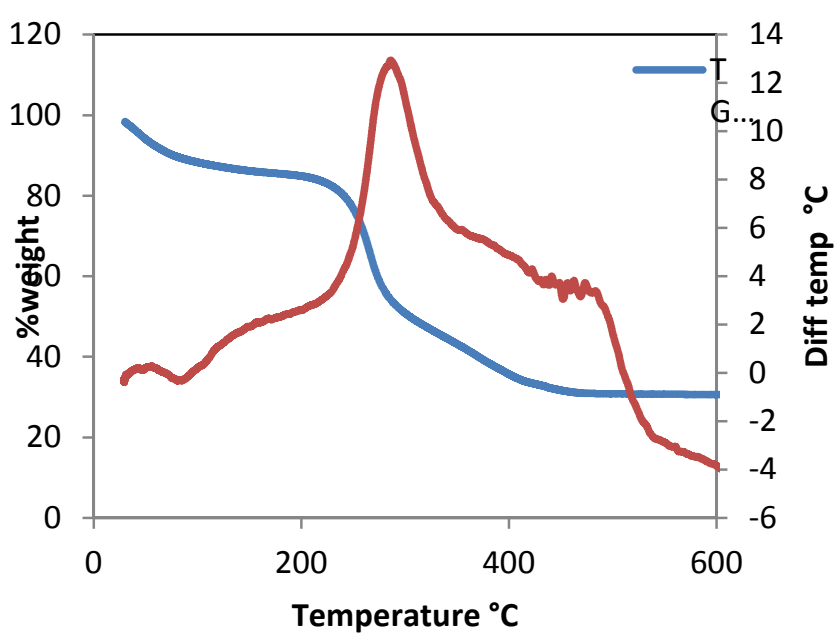

Gambar 1. Thermogram TG/DTA dari sampel yang dipreparasi pada kondisi $\mathrm{pH}=12$

Gambar 1 adalah termogram dari contoh senyawaan lignin yang diendapkan pada $\mathrm{pH}=$ 12. Perubahan yang paling signifikan dalam kurva TGA terjadi pada kisaran suhu 200$450^{\circ} \mathrm{C}$. Menurut kurva ini, terdapat dua buah reaksi dekomposisi yaitu pada kisaran suhu 200-300 ${ }^{\circ} \mathrm{C}$ dan $300-400^{\circ} \mathrm{C}$.

Pada reaksi pertama terjadi penurunan berat maksimum dan bersifat reaksi eksotermis, diasumsikan sebagai degradasi puncak dari senyawaan lignin ataupun senyawaan polimer alami sederhana lainnya. Pada reaksi yang kedua, kemungkinan dekomposisi senyawa logam-lignin atau senyawaan polimer alam yang kompleks lainnya. Selain itu, puncak kecil pada $100^{\circ} \mathrm{C}$ menandakan adanya penguapan air yang terikat secara fisis yang tidak tereliminir pada pengeringan contoh sebelum dianalisa TG/DTA.

Pada kisaran suhu $450{ }^{\circ} \mathrm{C}$ sampai $600{ }^{\circ} \mathrm{C}$, kurva TGA menerangkan sudah tidak ada penurunan berat contoh lagi, tetapi pada kurva DTA terlihat masih ada puncak eksotermik yang menunjukkan bahwa ada perubahan struktur tanpa perubahan berat molekul. Pada suhu $600{ }^{\circ} \mathrm{C}$, berat residu yang tersisa adalah sekitar 30 \% berat. 


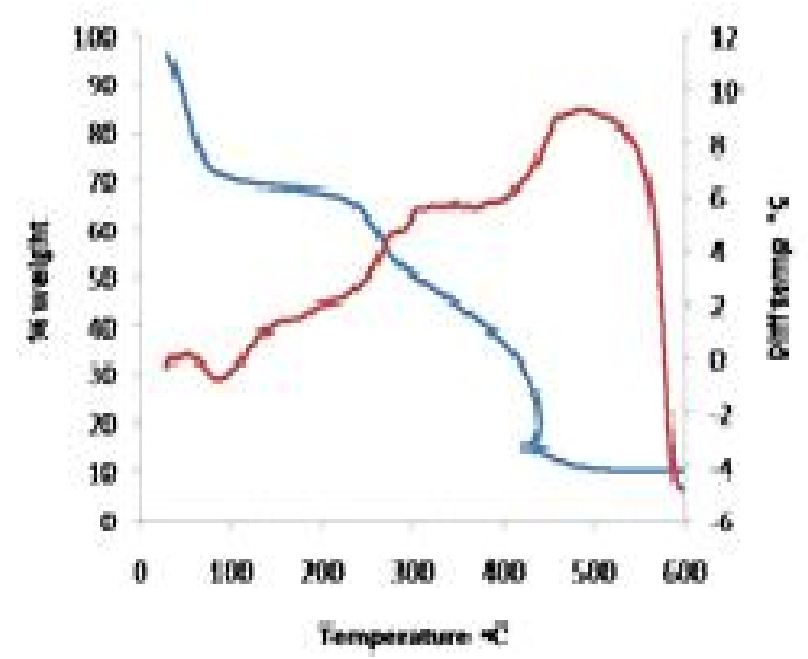

Gambar 2. Thermogram TG/DTA dari sampel yang dipreparasi pada kondisi $\mathrm{pH}=1$

Gambar 2 adalah termogram dari senyawaan lignin yang diendapkan pada $\mathrm{pH}=$ 1. Gambar 2 menunjukkan perilaku termal yang agak berbeda, dibandingkan dengan Gambar 1 . Dalam hal ini, di samping puncak pada suhu $100^{\circ} \mathrm{C}$, kurva penurunan berat badan maksimumnya muncul di kisaran suhu 250$450^{\circ} \mathrm{C}$. Dibandingkan dengan Gambar 1, puncak eksotermik yang terjadi pada kurva ini mempunyai luas area curva yang lebih luas dan berlangsung pada suhu yang lebih tinggi. Pada suhu $600^{\circ} \mathrm{C}$, berat residu yang tersisa adalah sekitar $10 \%$ berat.

Data di atas menjelaskan bahwa pada $\mathrm{pH}$ $=1$, produk lignin yang dihasilkan memiliki senyawaan yang tidak terbakar lebih sedikit dibanding dengan produk lignin yang dihasilkan pada $\mathrm{pH}=12$, hal ini dimungkinkan karena pada $\mathrm{pH}=1$ sebagian besar logam bebas berada pada fasa ionik dan dengan masih adanya senyawaan yang tidak terdekomposisi pada suhu $600^{\circ} \mathrm{C}$ kemungkinan adalah logam yang terkopresipitasi oleh endapan yang terjadi termasuk kandungan silika.

Pada kurva TGA di Gambar 2, teramati adanya seperti pendinginan mendadak sekitar suhu $425^{\circ} \mathrm{C}$ dan kemudian berjalan lagi seperti biasa, sedangkan pada kurva DTA terdapat kurva eksotermis yang cukup besar. Fenomena ini secara teoritis dapat dijelaskan sebagai proses pembakaran di mana pada saat sampel

mulai terbakar akan melepaskan sejumlah besar panas yang sangat cepat, menyebabkan peningkatan suhu yang tajam diikuti oleh pelepasan panas dan selanjutnya mengakibatkan penurunan suhu. Karena tidak ada penurunan lagi berat contoh, maka kemungkinan adanya reaksi yang bersifat katalitik dalam proses deformasi dimana logam bebas pada fasa ionik telah menjadi logam yang bersifat katalis aktif pada suhu ini.

\subsection{Analisa Temperatur Kalsinasi Terprogramkan (TPC)}

Analisa dengan TG memberi informasi bahwa pada suhu $450^{\circ} \mathrm{C}$ sampai dengan $600^{\circ} \mathrm{C}$ dari kedua sampel tidak menunjukkan adanya penurunan berat. Maka dalam analisa TPC ini, sampel yang lebih banyak di kalsinasi pada suhu $575^{\circ} \mathrm{C}$ selama 3 jam untuk menghasilkan material abu yang akan dianalisa unsur logamlogamnya dengan EDS/SEM. Kadar abu pada sampel kemudian di kumpulkan pada Tabel 1.

Tabel 1. Kadar abu dari sampel yang disiapkan pada $\mathrm{pH}=12$ dan 1 , setelah dikalsinasi $575{ }^{\circ} \mathrm{C}$ selama $3 \mathrm{jam}$

\begin{tabular}{cc}
\hline Kondisi Larutan awal & \% Abu \\
\hline $\mathrm{pH}=12$ & 28,88 \\
$\mathrm{pH}=1$ & 0,88
\end{tabular}

Membandingkan data kadar abu dari sampel yang di siapkan dengan kondisi $\mathrm{pH}$ yang berbeda (bersifat basa dan asam) seperti tertera pada Tabel 1 dengan hasil dari analisa dengan TG, terlihat bahwa metoda TPC ini menghasilkan kadar abu yang lebih rendah. Hal ini dimungkinkan karena jumlah sampel yang digunakan sangat jauh berbeda dimana metoda TPC mengunakan $5 \mathrm{~g}$ sampel kering dan TG menggunakan $0,2 \mathrm{~g}$ sampel kering.

\subsection{Analisa dengan EDS/SEM}

Tabel 2 adalah komposisi yang terkandung dalam abu yang dihasilkan dari larutan awal pada kondisi $\mathrm{pH}=12$ dan $\mathrm{pH}=1$, hasil identifikasi EDS. 
Tabel 2. Komposisi kandungan unsur anorganik dalam abu yang dihasilkan dari kondisi larutan awal yang berbeda

\begin{tabular}{ccc}
\hline \multirow{2}{*}{$\begin{array}{c}\text { UNSUR YANG } \\
\text { TERIKENTI- }\end{array}$} & \multicolumn{2}{c}{$\%$ W/W UNSUR } \\
\cline { 2 - 3 } & $\begin{array}{c}\text { LARUTAN } \\
\text { AWAL } \\
\text { pH=12 }\end{array}$ & $\begin{array}{c}\text { LARUTAN } \\
\text { AWAL } \mathbf{~ p H = 1}\end{array}$ \\
\hline $\mathrm{Na}$ & 2.3 & - \\
$\mathrm{Mg}$ & 1.3 & - \\
$\mathrm{Al}$ & 5.3 & 0.2 \\
$\mathrm{Si}$ & 18.0 & 0.4 \\
$\mathrm{~K}$ & 2.4 & - \\
$\mathrm{Ca}$ & 2.4 & 0.2 \\
$\mathrm{Fe}$ & 5.1 & - \\
$\mathrm{Cu}$ & 13.8 & 1.8 \\
$\mathrm{Zn}$ & 8.7 & - \\
\hline
\end{tabular}

Dari Tabel 2 dapat disimpulkan bahwa sampel yang dipreparasi dengan $\mathrm{pH}=12$ teridentifikasi masih mempunyai unsur anorganik yang cukup banyak (sembilan buah) yang jumlahnya relatif cukup besar brkisar dari $1-18 \% \quad(\mathrm{w} / \mathrm{w})$, sebaliknya sampel yang dipreparasi dengan $\mathrm{pH}=1$ teridentifikasi hanya mengandung empat unsur anorganik dalam jumlah yang sangat jauh lebih kecil berkisar antara 0,2-2 \%. Hasil ini menerangkan bahwa proses pemurnian lignin yang paling bagus adalah pada kondisi $\mathrm{pH}=1$.

\subsection{Analisa Ukuran Partikel (PSA)}

Kurva distribusi ukuran partikel dari lignin pada berbagai kondisi $\mathrm{pH}$ dapat dilihat pada gambar 3. Pada gambar 3 tergambarkan bahwa ukuran partikel rata-rata dari sampel lignin pada berbagai kondisi $\mathrm{pH}$ akan naik dengan turunnya kondisi $\mathrm{pH}$. Pada $\mathrm{pH}=12$ rata-rata ukuran partikelnya adalah $59 \mu \mathrm{m}$ dan pada $\mathrm{pH}=1$ adalah $262 \mu \mathrm{m}$. Data ini menunjukkan bahwa pembentukan partikel yang besar akan terjadi pada pengendapan dengan kondisi $\mathrm{pH}=1$ mengingat pada kondisi tersebut ion logam berada pada larutan dan akan terbentuk aglomerasi lignin lebih murni.

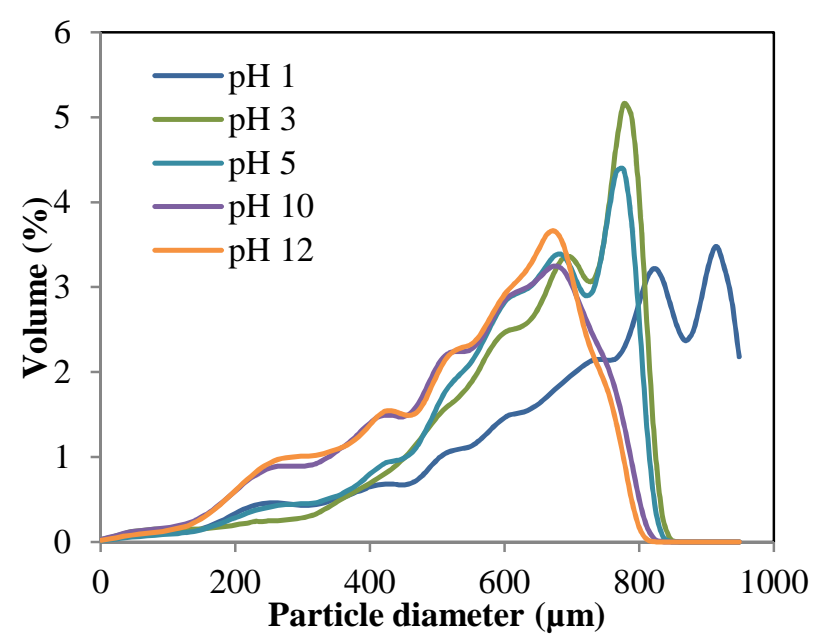

Gambar 3. Kurva distribusi ukuran partikel dari lignin pada berbagai kondisi $\mathrm{pH}$

Penelitian sebelumnya mendapatkan bahwa pada kondisi yang sama ukuran partikel rata-rata endapan lignin yang berasal dari contoh kraft lignin adalah $10 \mu \mathrm{m}$. Ukuran partikel lignin tergantung pada kondisi operasi pengendapan dan material dari sumber lignin tersebut. $^{[12]}$

\section{KESIMPULAN}

Dari hasil identifikasi dengan TG/DTA, TPC dan EDS ini dapat disimpulkan bahwa sampel yang dipreparasi dengan kondisi proses pada $\mathrm{pH}=1$ dapat menghasilkan lignin dengan kandungan pengotor logam yang minimal $(0.88 \%$ w/w) yang terdiri $\mathrm{Al}, \mathrm{Si}, \mathrm{Ca}$ dan $\mathrm{Cu}$ dan distribusi ukuran partikel yang lebih besar (262 $\mu \mathrm{m})$.

\section{UCAPAN TERIMA KASIH}

Penulis mengucapkan banyak terimakasih kepada Bpk Fauzan Aulia, ST. dan Harry Budiman, M.Sc. terhadap kontribusinya pada kelancaran teknik penelitian di laboratorium. Penelitian ini dibiayai oleh DIPA Pusat Penelitian Kimia-LIPI.

\section{DAFTAR PUSTAKA}

[1] R. Prado, X. Erdocia, L. Serano and J. Labidi. "Lignin purification with green 
solvents," Cellulose Chem.Technol., vol. 46 (3-4), pp. 221-225, 2012.

[2] M.A. Lake, "Potential Commercial Uses for Lignin." Southeastern Bioenergy Conference, August 2010.

[3] A.H. Setiawan. "Pemanfaatan lignin pada bidang makanan dan kosmetik." Prosiding SNKTI,vol 5, pp 124-128, 2013, ISSN: 2088-9828.

[4] Lignin Institute. "Lignin and its properties." http://mcbi.mml.nih.gov., vol. 9 (1), July 2001.

[5] Ö, Fredrik. "Precipitation and separation of lignin from kraft black liquor." Chalmers University of Technology Department of Chemical and Biological Engineering, Forest Products and Chemical Engineering, 1972, ISBN 917291-742-3.

[6] H. Budiman, A.H. Setiawan, "Isolation of natural polymer from the by-product of hydrolysis of oil palm empty fruit bunch for bio-ethanol production", Macromolecular Symposia, vol. 353 (1), pp. 220-224, 2013.

[7] A. Gracia, A. Toledano, L. Serrano, I. Egues, M. Gonzalez, F. Marin, J. Labidi. "Characterization of lignins obtained by selective precipitation." Cellulose Chem. Technol., vol. 46 (3-4), pp. 100-105, 2012.

[8] Ö, Fredrik, H. Theliander. "Filtration properties of lignin precipitated from black liquor." TAPPI Journal, vol. 6 (7), pp. 3-9, 2007.

[9] A.H. Setiawan, H. Budiman and F. Aulia. "The influence of heat and two stages precipitation in the process of natural polymer purification from the by product of bioethanol process base on empty palm fruit bunch." Advanced Material Research, vol. 1123, pp. 177-181, 2015. D.O.I.:10.4028/www.scientific.net/AMR. 1123.177

[10] E. Hermiati, M.A.R. Lubis, L. Risanto, R.P.B. Permana, L.H. Zaini. "Characteristics and Bond Performance of
Wood Adhesive Made from Natural Rubber Latex and Alkaline Pretreatment Lignin." Procedia Chemistry, vol. 16, pp. 376-383, 2015.

[11] Y. Meliana, A.H. Setiawan. "Antioxidant Activity of Lignin Phenolic Compounds as byproduct of Pretreatment Process of Bioethanol Production from Empty Fruits Palm Bunch." AIP Conference Proceedings 1712.050010, 2016. D.O.I.: 10/1063/1.4941893.

[12] Cazacu, M. Capraru and V.I. Popa. Advances Concerning Lignin Utilization in New Materials. Advances in Natural Polymer, Composites and Nanocomposites, pp. 80-284, 2012. 